Vol.45, Special n. : pp. 45-55, September 2002

ISSN 1516-8913 Printed in Brazil

\title{
Bone-seeking Therapeutic Radiopharmaceuticals
}

\author{
Suresh C. Srivastava* \\ Brookhaven National Laboratory; Medical Department; Building 801; P.O. Box 5000 Upton; 11973-5000; \\ New York-USA; suresh@bnl.gov
}

\begin{abstract}
Bone-seeking therapeutic radiopharmaceuticals are utilized on the basis of the radionuclide's particulate emissions (primarily low to intermediate beta emission). The requirements therefore are different from those of bone imaging agents that consist mainly of short-lived single photon emitters. Lately, the therapeutic bone seeking radiopharmaceuticals have attained increasing importance due to their potential role in alleviating pain from osseous metastases in cancer patients, for the treatment of joint pain resulting from inflamed synovium (radiosynoviorthesis, or radiosynovectomy), or from various other forms of arthritic disease. There is, however, a paucity of published data on the bio-pharmacokinetics of these agents when used following intravenous administration for bone pain palliation. This paper will briefly review and summarize the presently available chemical and biopharmacokinetic information on the various clinically approved as well as experimental bonelocalizing therapeutic radiopharmaceuticals, and make projections on their clinical application for the treatment of primary/metastatic cancer in bone.
\end{abstract}

Key words: Therapeutic radiopharmaceuticals, Bone seekers, Pain palliation, Bio-pharmacokinetics, Radiosynovectomy

\section{INTRODUCTION}

Therapeutic radiopharmaceuticals are utilized on the basis of the therapeutic electron emissions of particular radionuclides, some of which may also emit imaging photon(s). The interest in application of radionuclides to therapy of bone malignancies, particularly for palliative relief of bone pain, is not new, but has recently undergone a renewal. It had its origin in the earliest days of the nuclear era but fell into relative obscurity for some time, until about a decade ago. Both strontium- 89 and phosphorus-32 were investigated as early as the 1940's for the treatment of metastatic cancer to bone (Pecher, 1942; Friedell and Storaasli, 1950). The work of Firusian et al. (1976) suggested again that strontium- 89 would be useful for relief of pain secondary to osseous metastases. Robinson and others further explored the utility of strontium-89 (Robinson, 1986; Quilty et al, 1994; Lewington et al., 1991; Robinson, 1987) resulting in the FDA approval for its routine application in 1993. This work has also stimulated clinical research in order to find other radionuclides, which may have improved physical properties that permit treatment with fewer side effects on the myeloproliferative

\footnotetext{
* Author for correspondence
} 
cells in the bone marrow. This paper will compare the several agents that may be useful in treatment of bone malignancy and discuss possible ways in which they may be applied to provide increased benefits to patients. A short discussion of radiosynovectomy is also included.

The basis for the action of these therapeutic agents is their incorporation into bone mineral and their beta emission, which limits their range of action to the near neighborhood of their increased concentration in pathological areas such as metastases where the attempt at healing by the bone results in increased uptake. ${ }^{117 \mathrm{~m}}$ Tin is an exception in that its emission consists primarily of conversion electrons rather than beta particles. Table 1 lists the currently used isotopes (either approved or being investigated) for bone pain palliation and their nuclear and physical characteristics. These same radionuclides, in addition to a few others described in a later section, also have properties that make them useful for radiosynovectomy.

\section{BONE PAIN PALLIATION}

\section{Desirable Radionuclide Characteristics}

Half-life: The half-life of a radionuclide will determine the initial dose rate and therefore the total amount of radioactivity to be administered. What is an appropriate physical $\mathrm{T}^{1} / 2$, is not well understood. A higher initial dose rate may result in more effective cell killing, but the therapeutic ratio of malignant cell destruction to normal cell recovery may be less. Too long a $\mathrm{T}^{1 / 2}$ creates obvious problems in environmental safety in case of spill or early death of the patient. A very short $\mathrm{T}^{1 / 2}$ is problematic so far as shipping and shelf life are concerned. It also requires a larger total of administered activity, which increases the radiation dose to personnel and family members and may require some hospitalization, thus increasing cost. On the other hand, repetitive doses may be given at shorter intervals making it possible to titrate dose to response.
Photon Emission: Accompanying photon emissions of the appropriate energy can be useful in monitoring the distribution of the radiopharmaceutical in the patient for assessing dosimetry, but are not essential. They also constitute a source of exposure to personnel and family, but this has not been a significant problem with the radionuclides investigated to date.

Electron Emission: Both strontium-89 and phosphorus-32, the earliest radionuclides used for this purpose, have highly energetic beta emissions. These penetrate deeply into the marrow cavity and may be the cause of increased myelotoxicity. More recent research has concentrated on radionuclides, which have much lower energy electron emissions and therefore, potentially reduced toxicity.

Other Factors: Ease of preparation, in-vitro and invivo stability, shelf life, and cost are other considerations. Radionuclides, which can be prepared in a reactor, are usually less costly. Ease of preparation and cost are dependent on the nuclear reactions and subsequent radiochemical processing required for manufacture.

\section{Comparison of Radiopharmaceuticals}

The relevant physical characteristics of the various radionuclides are given in Table 1. Strontium-89 chloride (Metastron) and Samarium-153 EDTMP (Quadramet) have been approved by the Food and Drug Administration within the last ten years. Phosphorus-32 as sodium phosphate was grandfathered as an approved drug when the FDA took over jurisdiction of radiopharmaceuticals from the Atomic Energy Commission many decades ago. Since P-32 is often used as a baseline for comparison, it will be discussed first. Rhenium-186 (which is approved in many nonU.S. countries), Re-188-HEDP, and Tin- $117 \mathrm{~m}$ Stannic DTPA are still under investigation in the U.S. Other newer radiolanthanide metals, such as Ho-166, and Lu-177, etc. are also undergoing investigation but will not be covered here since there is a paucity of definitive clinical and pharmacokinetic information in the literature on these agents. 
Phosphorus-32: Phosphorus-32 as sodium phosphate $\left(\mathrm{NaH}_{2} \mathrm{PO}_{4}\right)$, as mentioned earlier, was the earliest used agent for palliation of pain from osseous metastases. Originally it was believed that its effect was mainly from incorporation into the tumor itself. However, the tumor to non-tumor ratio is not very favorable and the relief of pain is primarily because of its uptake into bone mineral, not the tumor. In addition, uptake is higher in any rapidly dividing tissue such as bowel, but particularly so in the red marrow itself in addition to involved bone. Therefore, the bone to marrow ratio is low. Similar to Sr-89, P-32 has a highly energetic beta emission, and has no accompanying gamma photon making monitoring somewhat difficult. Results have been similar to $\mathrm{Sr}-89$, but toxicity to the bone marrow has been severe at therapeutic level administrations. Phosphorus-32 has also been used in therapy of polycythemia vera and leukemia. Most of the information in patients in regard to localization and dosimetry has come from studies in such patients.

Table 1 - Physical and nuclear characteristics of bone-seeking therapeutic radionuclides ${ }^{1}$.

$\begin{array}{ccccc}\text { Maximum } \beta^{-} & \begin{array}{c}\text { Average } \beta^{-} \\ \text {energy }\end{array} & \begin{array}{c}\text { Average } \\ \text { Range }\end{array} & \mathrm{T}_{1 / 2} & \gamma \text { photon } \\ \text { energy } & (\mathrm{MeV}) & (\mathrm{mm}) & (\text { days }) & (\mathrm{MeV})\end{array}$

\begin{tabular}{llllll}
\hline Strontium-89 & 1.46 & 0.58 & 2.4 & 50.5 & None \\
Phosphorus-32 & 1.71 & 0.70 & 3.0 & 14.3 & None \\
Tin-117m & $0.13^{2}$ & --- & 0.22 & 14.0 & $0.159(86 \%)$ \\
Erbium-169 & $0.15^{2}$ & --- & 0.29 & & \\
Lutetium-177 & 0.34 & 0.11 & 0.30 & 9.3 & None \\
Rhenium-186 & 0.50 & 0.14 & 0.35 & 6.7 & $0.208(11 \%)$ \\
Samarium-153 & 1.08 & 0.33 & 1.05 & 3.7 & $0.137(9 \%)$ \\
Holmium-166 & 0.81 & 0.22 & 0.55 & 1.9 & $0.103(29 \%)$ \\
Rhenium-188 & 1.84 & 0.67 & 3.3 & 1.1 & $0.081(6 \%)$ \\
\hline
\end{tabular}

${ }^{1}$ Arranged in order of decreasing half-life

${ }^{2}$ Conversion electrons with discrete energies (and range).

Pharmacokinetics: The absence of any gammaemitting isotope of phosphorus has made a study of its distribution and biokinetics in human beings extremely difficult. In a study in albino rats, Friedell and Storaasli (1950) showed that most of the intraperitoneally administered ${ }^{32} \mathrm{P}$ was taken up in the skeleton with lesser amounts in muscle, digestive tract, liver, skin and brain. There was no separation of skeleton into bone and red marrow.
After two weeks, $46 \%$ of the administered activity had been excreted: $33 \%$ was in bone and $20 \%$ in the viscera and musculature. The authors determined that the biologic half-life for activity in the soft tissues was about 9 days and over 10 days for bone (bone and marrow ?).

The differential absorption ratio of radioactive phosphorus in patients with cancer of the breast, sarcoma of bone, and lymphoma, was studied by 
Kennedy et al. (1941). This ratio was defined as the difference in concentration in the tissue examined compared to what the concentration would be if the ${ }^{32} \mathrm{P}$ were to be distributed evenly throughout the body. These ratios for breast cancer tissue ranged from 0.8 to 1.9 in 5 patients from 1 to 5 days after administration, whereas in normal breast tissue the ratio was 0.2 to 0.4 . On the other hand, the ratio in osteogenic sarcoma was much higher, usually from 2.6 to as high as 8.3. Normal bone differential absorption ratios were mostly less than one. In some tumor specimens the ratio was less than one, attributable to the presence of necrosis in the specimens. It should be noted that 3 out of 5 patients had had considerable preoperative radiation some time prior to the surgery at which the specimens were obtained.

Strontium- 89 chloride: Strontium-89 is a pure beta emitter. The maximum beta energy is high and penetration (average) in soft tissue is $2.4 \mathrm{~mm}$. The long physical half-life means that low administered activity is given resulting in a rather low initial dose rate. In addition, it limits the possibility of repeat doses until much after the initial dosing. Nevertheless, it has proven effective (Lewington et al., 1991; Robinson et al., 1987; McEwan, 1994; Katin et al., 1993). Absence of an accompanying gamma photon makes it difficult, but not impossible, to monitor distribution. The energetic betas result in a low bone to marrow dose ratio but myelotoxicity has not been a major factor. While individual studies vary in results, the overall efficacy in terms of patients experiencing pain relief (complete + marked + moderate) appears to be in the range of $54 \%$ (McEwan, 1994) to $80 \%$ (Robinson et al., 1987).

Pharmacokinetics: Despite its approved status by the United States Food and Drug Administration (Metastron ${ }^{\circledR}$, Amersham Healthcare, Arlington Heights, IL), there is a paucity of data on the biokinetics of ${ }^{89} \mathrm{Sr}$. Much of the early work on biodistribution was performed in order to better understand calcium metabolism and also to predict the effects of fallout from nuclear tests.
Consequently, these studies were performed following oral administration. In addition, the lack of gamma photons has made it difficult to obtain data regarding information gleaned from imaging studies of whole body and specific organ distribution, although ${ }^{85} \mathrm{Sr}$ with a physical half-life of 65 days has been used as a gamma-emitting tracer. Furthermore, studies have been mostly in pathological situations, which makes each case unique unto itself. Cohn et al. (1963) compared the kinetics of ${ }^{85} \mathrm{Sr}$ as the chloride with ${ }^{47} \mathrm{Ca}$ chloride in a group of patients with various benign conditions. Significant differences between calcium and strontium were observed. Much more of the calcium was retained in the body and the renal clearance was lower. Over the period from 2 to 10 days after intravenous administration there was a total body loss of $5.54 \%$ per day of the strontium. This decreased to an average of $1.76 \%$ per day in the period 10 to 30 days after administration. Renal clearance was 8.22 liters/day in the period 5-10 days after administration and a total of $39.8 \%$ of strontium was excreted in the urine in the first 10 days. Fecal excretion during this same period was $13.0 \%$. Strontium was excreted preferentially by the kidneys, in contrast to calcium. Consequently, whole body retention was less for strontium. There was a higher percentage of calcium retained in plasma and soft tissues. However, accretion rates into bone were similar for the two elements. Marshall (1972) described a model of strontium metabolism using a power function for whole body retention. The components of such a function were as follows: apposition-absorption rate $=2.4 \%$ per year; resorption rate of cancellous bone $=9.5 \%$ per year. A complication of assessing kinetics of ${ }^{89} \mathrm{Sr}$ is the long physical half-life. For radionuclides with a shorter half-life, the distribution in bone can be calculated as $50 \%$ on the surface of compact bone and $50 \%$ on the surface of trabecular bone. However, with the longer-lived radionuclides such as ${ }^{89} \mathrm{Sr}$, the distribution must be considered on a volume rather than a surface basis. Therefore, the later time distribution is in a ratio of $4: 1$, compact to trabecular bone. Ten subjects were studied by Uchiyama et al. (1973) after intravenous 
administration of ${ }^{85} \mathrm{Sr}$. Six of these had a diagnosis of osteoporosis. Retention was determined by measuring urinary and fecal excretion over a period of 8 to 13 days. The retention curves were fitted by a sum of two exponential functions. The more rapid component (4.4-98.4\%) varied with a $\mathrm{T}^{1} / 2$ from 0.2 to 1.3 days. The $\mathrm{T}^{1} / 2$ of slower component (50.5-92.5\%) varied from 28.6-101.9 days. Breen et al. (1992) studied 5 males with prostate carcinoma with variable extent of disease. They measured whole body retention by means of urinary activity levels over a period of 6 days, and evaluated blood levels over a period of 7 days. Imaging was performed in 4 of the subjects using the far from ideal ${ }^{85} \mathrm{Sr}$. Whole body images were obtained at intervals for up to 8 weeks. While actual numbers are not given in the report, there was a wide disparity in whole body retention after 4 days, ranging from about $50 \%$ to $92 \%$. The fraction of administered activity in the plasma at 1 day and beyond showed much less variation. The renal plasma clearance rates varied from $8.3 \pm 3$ liters per day to $12.8 \pm 1.7$ liters per day. Although imaging indicated that there was some bowel excretion, it could not be quantified and did not enter into dose calculations. Concentration of strontium in bone lesions was from 2 to 25 times that in normal bone. The biological half times were also very variable. In normal bone they ranged from $20 \pm 4$ to $137 \pm 27$ days while in metastatic sites the range was from $20 \pm 1$ to $104 \pm 14$ days.

Samarium-153 EDTMP: This radiopharmaceutical has a short physical half-life of 1.9 days. This can be advantageous in that it is easier to administer repeated doses. However, it makes manufacturing and delivery a more difficult problem. The range of its beta particles is short (average $0.55 \mathrm{~mm}$ ) resulting in good bone to marrow ratios ranging between 2-5.5. Myelotoxicity has been manageable at the approved dose schedule (1 $\mathrm{mCi} / \mathrm{kg}$ ), and efficacy is in a similar range as $\mathrm{Sr}-89$ (Turner and Claringbold, 1991; Farhangi et al., 1992; Collins et al., 1993; Resche et al., 1997). At high levels of administered Sm-153, an increase in survival of patients with metastatic prostate cancer was demonstrated, but at the cost of severe myelotoxicity (Collins et al., 1993).

Pharmacokinetics: A series of chelates labeled with ${ }^{153} \mathrm{Sm}$, an easily produced radionuclide, was studied by Goeckler et al. (1987) for the purpose of developing an agent with a relatively short physical half-life, beta emissions with a short range in tissue in order to reduce marrow dose, and a suitable gamma emission for monitoring distribution. The chelate, which gave the best distribution in rats, was ethylenediaminetetramethylene phosphonate (EDTMP). It was found that $57.71 \pm 4.04 \%$ was deposited in the skeleton, while blood activity was $0.032 \pm 0.016 \%$ and liver was $0.252 \pm 0.038 \%$ of administered activity at 2 hours. The bone/blood ratio was $1833 \pm 1274$ and bone/muscle ratio $1459 \pm 505$. Urinary excretion was even more rapid than with 99mTc MDP with excretion complete by 2 hours. Bone uptake reached a maximum at 1 hour. Studies in human beings (Singh et al., 1989) showed nearly identical distribution of ${ }^{153} \mathrm{Sm}$ EDTMP and ${ }^{99 \mathrm{~m}}$ Tc MDP with very similar lesion to normal bone ratios. The percent administered activity remaining in whole blood was $5.17 \pm 1.05 \%$ at 2 hours and $2.09 \pm 0.52 \%$ at 4 hours. Cumulative urinary excretion was over $50 \%$ by 8 hours and remained unchanged thereafter. A somewhat larger series of patients was studied by Bayouth et al. (1994). The initial $T^{1} / 2$ of blood disappearance was $5.5 \pm 1.1$ minutes and a slower component was $65.4 \pm 9.6$ minutes. They found less than $1 \%$ of the injected activity remaining in blood at 5 hours. Skeletal uptake averaged $52.2 \pm 18.0 \%$. The biological $\mathrm{T}^{1} / 2$ for whole body retention (assumed to be in the skeleton) was determined to be 520 hours.

Rhenium-186 HEDP: The physical half-life of rhenium-186 is 3.7 days. This is long enough that shipment and shelf life are less of a problem than with samarium-153. It is short enough that repeated doses could be given over a relatively short period of time. However, the average beta energy is considerably higher than that of samarium-153, and consequently the range is 
longer so that, at least theoretically, it is less sparing of the bone marrow. The dose ratio of bone to marrow is not particularly favorable and the compound is less stable than the other radiopharmaceuticals under discussion (Maxon et al., 1990; deKlerk et al., 1992).

Pharmacokinetics: Rhenium-186 has energetic beta emissions as well as a photon suitable for gamma imaging (Table 1). This combination suggested its usefulness for therapy in painful bony metastases. Methods for labeling the radionuclide to hydroxyethylidene diphosphonate (HEDP) were studied by Mathieu (1979) and Eisenhut (1982). The first studies in humans were reported by Maxon (1988). These studies were performed on patients with extensive bone involvement by malignancy. Therefore, the distribution is not exactly that which would be obtained in normal individuals and is extremely variable from one patient to another. Distribution was very similar to ${ }^{99 \mathrm{~m}} \mathrm{Tc}$ MDP images performed on the same patients. Blood disappearance was rapid with $14 \%$ of administered activity remaining at 30 minutes. Cumulative renal excretion was $45 \%$ at 5 hours and $71 \%$ by 3 days. A more detailed study of pharmacokinetics was carried out by de Klerk et al. (1992) in 17 patients. The fraction of the cleared radioactivity averaged 0.69 with a standard deviation of 0.15 . In 24 hours there was a total urinary excretion of $71 \pm 6 \%$. Protein binding of ${ }^{186}$ RE-HEDP in plasma was found to increase with time from $51 \pm 6 \%$ to $89 \pm 5 \%$. Other pharmacokinetic values are shown in Table 2 . These authors also utilized the bone scan index (BSI) of Blake (1988). There was, as expected, a good correlation of the BSI with the non-renal fraction of activity and with the volume of distribution.

Table 2 - Pharmacokinetics of rhenium-186 HEDP.

\begin{tabular}{lccc}
\hline \multicolumn{1}{c}{ Parameter } & Blood & Plasma & $\begin{array}{c}\text { Plasma } \\
\text { Water }\end{array}$ \\
\hline Half-life $(\mathrm{h})$ & $40.1 \pm 5.0$ & $41.0 \pm 6.0$ & $29.5 \pm 6.4$ \\
Total clearance $(\mathrm{m} 1 / \mathrm{min})$ & $40 \pm 13$ & $28 \pm 9$ & $145 \pm 38$ \\
Renal clearance $(\mathrm{m} 1 / \mathrm{min})$ & $26 \pm 6$ & $18 \pm 4$ & $96 \pm 21$ \\
Non-renal clearance. $(\mathrm{ml} / \mathrm{min})$ & $14 \pm 10$ & $10 \pm 7$ & $48 \pm 31$ \\
Distrib. Vol. $(\mathrm{L} / \mathrm{kg})$ & & $1.1 \pm 0.5$ & \\
\hline
\end{tabular}

Adapted from de Klerk et al. (1992): Values are mean \pm SD.

Tin- $117 \mathrm{~m}$ Stannic DTPA: At this time only limited clinical experience has been obtained with this compound (Atkins et al., 1993; Atkins et al. 1995; Krishnamurthy et al., 1997; Srivastava et al., 1998). Its physical characteristics are very favorable. The range of the electron emission (monoenergetic conversion electrons) is less than that of any of the other compounds so that the radiation absorbed dose to the marrow is considerably less, giving the best bone to marrow ratio (Table 3). The initial dose rate is higher than that obtained with strontium- 89 and the half-life is ideal so far as shipment and shelf life are concerned. Its in-vitro and in-vivo stability are very high (Srivastava et al., 1994). An accompanying gamma photon is useful for monitoring. Results so far indicate a very low myelotoxicity (Table 4) and the efficacy is similar to the other compounds (Srivastava et al., 1998). 
Table 3 - Dosimetry of bone agents*

\begin{tabular}{ccc}
\multicolumn{2}{l}{ Radiation Dose, $\mathrm{rad} / \mathrm{mCi}$} & \\
\hline Bone & Red & Bone/Marrow Dose \\
Surfaces & Marrow & Ratio
\end{tabular}

$\begin{array}{lrrr}\text { Strontium-89Cl } & & 40.7 & 1.6 \\ \text { Rhenium-186 HEDP } & 63.0 & 3.0 & 2.3 \\ \text { Samarium-153 EDTMP } & 7.0 & 2.8 & 5.5 \\ \text { Tin-117m Stannic DTPA } & 15.4 & 9.8 & 6.6\end{array}$

*Data from literature (Srivastava et al., 1998).

Pharmacokinetics: Tin- $117 \mathrm{~m}$ differs from the other therapeutic agents in that its primary emission is conversion electrons of discrete energies. These are also accompanied by an excellent gamma photon for monitoring distribution. The limited penetration of conversion electrons theoretically should reduce the absorbed dose to the red marrow. Studies in animals (Srivastava et al., 1985) demonstrated that the stannic form of Sn-DTPA behaved much differently from the stannous form. It was not rapidly excreted into the urine, as expected, but it is retained to a considerable extent in bone. Further studies (Oster et 1., 1985) showed that its behavior mimicked that of ${ }^{99 \mathrm{~m}} \mathrm{TC}$ MDP in certain pathological conditions. The biodistribution was studied in a group of patients with advanced metastatic disease from various primary malignancies.

Table 4 - Myelotoxicity Levels of Radiopharmaceuticals for Bone Pain Palliation (Srivastava et al., 1998).

Dose Group

Radiopharmaceutical

$(\mathrm{mCi} / \mathrm{Kg})$
No of Patients with Grade $\geq 2$

Toxicity

WBC Platelets

\begin{tabular}{|c|c|c|c|c|c|}
\hline $\mathrm{Sr}-89 \mathrm{Cl}_{2}$ & $\begin{array}{l}0.154 \\
0.040\end{array}$ & $\begin{array}{l}67 \\
161\end{array}$ & $\begin{array}{c}25(37 \%) \\
-----48\end{array}$ & 41 & (61\%) \\
\hline Re-186-HEDP & $0.500-1.143$ & 12 & $2(17 \%)$ & 3 & $(25 \%)$ \\
\hline Sm-153-EDTMP & $\begin{array}{l}1.00 \\
1.50 \\
3.00\end{array}$ & $\begin{array}{r}20 \\
4 \\
4\end{array}$ & $\begin{array}{ll}3 & (15 \%) \\
3 & (75 \%) \\
4 & (100 \%)\end{array}$ & $\begin{array}{l}5 \\
1 \\
2\end{array}$ & $\begin{array}{l}(25 \%) \\
(25 \%) \\
(50 \%)\end{array}$ \\
\hline Sn-117m DTPA & $\begin{array}{l}0.143 \\
0.179 \\
0.286\end{array}$ & $\begin{array}{r}9 \\
5 \\
12\end{array}$ & $\begin{array}{ll}1 & (11 \%) \\
0 & (0 \%) \\
1 & (8 \%)\end{array}$ & $\begin{array}{l}0 \\
0 \\
0\end{array}$ & $\begin{array}{l}(0 \%) \\
(0 \%) \\
(0 \%)\end{array}$ \\
\hline
\end{tabular}

${ }^{1}$ Using NCI criteria.

20nly hematological toxicity@grade $\geq 2$ mentioned.

The disappearance rate from blood appeared to be considerably slower than other bone agents and urinary excretion slower. However, because of its rather long physical half-life relative to these biologic parameters, this is not a problem for radiation absorbed dose estimates. Once localized 
in bone, the ${ }^{117 \mathrm{~m}} \mathrm{Sn}$ appears to remain fixed with no or extremely slow release other than through physical decay (Atkins et al., 1993). Approximately $70 \%$ is taken up by bone, but this is highly variable and depends on the extent of disease. Imaging studies have shown no focus of uptake other than bone. The biologic parameters are shown in Table 5.

Table 5 - Pharmacokinetics of Sn-117m(4+)DTPA (Krishnamurthy et al., 1997).

\begin{tabular}{|c|c|c|c|c|}
\hline \multirow{2}{*}{ Component } & \multicolumn{2}{|c|}{ Plasma disappearance } & \multicolumn{2}{|c|}{ Urinary excretion } \\
\hline & $\mathrm{T} 1 / 2(\mathrm{~h})$ & $\%$ & $\mathrm{~T} 1 / 2$ & $\%$ \\
\hline 1 & $5.4 \pm 2.1$ & $81.8 \pm 3.7$ & 38.6 & 29.8 \\
\hline 2 & $102.6 \pm 15.3$ & $18.2 \pm 3.7$ & 796.7 & 70.2 \\
\hline
\end{tabular}

\section{THERAPY OF CANCER IN BONE}

The compounds discussed above have been considered primarily as agents to provide pain palliation in far advanced metastases involving bone. The requirements for achieving this purpose are rather modest. It is not necessary to obtain much tumor regression and it is desirable to avoid significant toxicity. Therefore, for achieving pain palliation, it is not necessary to administer the highest doses possible.

However, there are hints that more than just pain palliation can be achieved in the appropriate clinical situation. Our data indicate that an earlier onset of response occurs with higher levels of administered tin- $117 \mathrm{~m}$ activity (Srivastava et al., 1998). The Trans-Canada Study performed with high doses of strontium-89 in patients with relatively early metastatic disease of the prostate demonstrated that, as an adjuvant to external beam treatment, the interval to new painful metastases could be significantly lengthened (Porter et al., 1993). In addition, others have demonstrated reversal of changes on the radionuclide bone imaging study with strontium-89 (Robinson et al., 1989). Radiographs following radionuclide therapy have shown healing of lytic metastases (Friedell and Storaasli, 1950; Fossa et al., 1992) thus demonstrating that tumor regression actually can occur. It has also been shown that treatment of earlier disease is more successful than the treatment of more advanced disease. Prolongation of survival has been reported using very high doses $(2.5 \mathrm{mCi} / \mathrm{kg})$ of samarium-153 EDTMP (Collins et al., 1993). This has been attained at the expense of increased morbidity as evidenced by greater increase in myelotoxicity.

On the basis of these findings it is reasonable to look at these agents in other situations. They may be very useful as adjuvant to external beam radiation therapy and chemotherapy. In primary bone malignancy the use of radionuclide therapy as an adjuvant to surgery may prevent the appearance of metastatic disease. Earlier application of these agents in a prophylactic mode appears warranted. Their ease of administration and relative lack of toxicity present a strong argument for this approach. If higher doses do prove to be advantageous, then that agent with the lowest toxicity should be considered as the most appropriate candidate. Tin- $117 \mathrm{~m}$ stannic DTPA appears to be the agent of choice if future studies (an extended Phase II/Phase III clinical trial is underway) continue to demonstrate reduced toxicity compared to the other agents, in particular strontium-89 and samarium-153. In summary, going beyond bone pain palliation, the use of these bone-seeking radiopharmaceuticals to actually treat the primary/metastatic cancer in bone is considered to be a very attractive prospect.

\section{RADIATION SYNOVECTOMY}

Radiation synovectomy is an attractive alternative to chemical or surgical synovectomy for the treatment of inflammatory synovial disease, including rheumatoid arthritis, as well as to some extent, osteoarthritis. The procedure entails a single injection of a beta-emitting radiopharmaceutical directly into the synovium to 
control and ablate inflammation. The injected agents, typically colloids or larger aggregates, are assumed to be rapidly phagocytized by synoviocytes and then distributed within the synovium, primarily at the surface. The most common agents have been radiocolloids or macroaggregates employing high-energy beta emitters, Y-90, Au-198, Dy-165, and Re-186 (Deutsch et al., 1993). While these agents have shown good results, they are not widely used especially in the United States. All display some degree of leakage of the radionuclide from the joints leading to an increased radiation dose to normal organs. The size of these radiolabeled particles cannot be adequately controlled during formation, and it is assumed that small $(<10 \mu \mathrm{m})$ particles leak from the synovium over time. However, a new type of particle, made from hydroxyapatite (HA), a natural constituent of bone, has become commercially available in various controlled sizes ranging from $1-80 \mu \mathrm{m}$. Research interest has thus focused recently on incorporating HA particles into new agents for radiation synovectomy. Initial studies in rabbits with antigen-induced arthritis (AIA) using Sm-153 labeled HA, showed minimal leakage of activity $(0.09 \%$ over four days) from the treated joint compared to leakage rates obtained with other radiocolloid agents (5-45\%). Results with Re-186HA, however, showed $3.05 \%$ leakage over four days (Chinol et al., 1993).

The presumed heterogeneous distribution of radionuclide within the synovium has limited existing agents to only those labeled with highenergy beta emitters. It is presumed that the longer range of these particles is necessary to treat medium to large sized joints. However, lowenergy beta emitters may be equally or more effective in reducing inflammation for small to medium joints since a much larger radiation dose could be delivered to the synovium without excessive irradiation of surrounding tissue. This could be analogous to the effectiveness of the short-range conversion electrons from $\mathrm{Sn}-117 \mathrm{~m}$ for bone pain palliation, compared to the highenergy beta emitter Sr-89 (Srivastava, 1996; Srivastava and Dadachova, 2001). The only clinical examples to date for treating synovial inflammation using a low-energy beta emitter is the use of Er-169 ( ${ }^{-}$avg $111 \mathrm{keV}$ ) colloids to treat inflammation in the small finger joints (Deutsch et al., 1993). Based on various considerations, appropriate-size particles labeled with Sn-117m, Sm-153, and Er-169 would seem to be the agents of choice for radiation synovectomy.

\section{RESUMO}

Radiofármacos para terapia em nível ósseo são utilizados devido a emissão de radiação particular pelo radionuclídeo (primariamente beta de baixa e média). Portanto, as necessidades são diferentes daquelas usadas para imagem óssea que consiste principalmente de emissores de fótons de meiavida curta. Ultimamente, a terapia do esqueleto com radiofármaco tem alcançado uma importância crescente devido ao papel em potencia de aliviar a dor de metástases ósseas em pacientes com câncer, para o tratamento de dor nas articulações devido a inflamação sinovial sinovite (radiosinovite ou radiosinovectomia), ou de várias outras formas de doenças articulares. Portanto, existe uma falta de publicações sobre a bio-farmacocinética desses agentes quando administrados intravenosamente como paliativo para dor óssea. Este artigo irá revisar rapidamente e resumir as informações sobre a química e a biofarmacocinética dos vários radiofármacos aprovados clinicamente e em experimentação disponíveis até o presente momento para terapêutica do esqueleto e fazer projeções para o tratamento clínico do câncer primário/metastático no osso.

\section{ACKNOWLEDGEMENTS}

This work was supported by the United States Department of Energy, Office of Health and Environmental Research, under Contract No. DEAC02-98CH10886. The assistance of Ms. Amalia Ruggiero in the preparation of this manuscript is gratefully acknowledged.

\section{REFERENCES}

Atkins, H. L.; Mausner, L. F. and Srivastava, S. C. et al. (1993), Human biodistribution of Sn-117m(4+) DTPA; a new agent for palliative treatment of painful osseous metastases. Radiologyi, 186, 279-283.

Atkins, H. L.; Mausner, L. F. and Srivastava, S. C. et al. (1995), Tin-117m(4+)DTPA for palliation of pain from osseous metastases: a pilot study. J. Nucl. Med., 36, 725-729. 
Breen, S. L.; Powe, J. E. and Porter, A. T. (1992), Dose estimation in strontium-89 radiotherapy of metastatic prostatic carcinoma. J. Nucl. Med., 33, 1316.

Blake, G. M.; Zivanovic, M. A.and Blaquire, R. M. et al. (1988), Strontium-89 therapy: measurement of absorbed dose to skeletal metastases. J. Nucl. Med., 29, 549-557.

Bayouth, J. E.; Macey, D. J.; Kasi, L. P. and Fassella, F.V. (1994), Dosimetry and toxicity of samarium153-EDTMP administered for bone pain due to skeletal metastases. J. Nucl. Med., 35, 63-69.

Chinol, M.; Vallabhajousula, S. and Goldsmith, S. et al. (1993), Chemistry and Biological Behavior of Samarium-153 and Rhenium-186- labeled Hydroxyapatite Particles: Potential Radiopharmaceutical for Radiation Synovectomy. J. Nucl. Med., 34, 1536.

Cohn, S. H.; Lippincott, S. W.; Gusmano, E. A. and Robertson, J. S. (1963), Comparative kinetics of $\mathrm{Ca}^{47}$ and $\mathrm{Sr}^{\mathbf{8 5}}$ in man. Radiat. Res., 19, 104-119.

Collins, C.; Eary, J. F. and Donaldson, G. et al. (1993), Samarium-153-EDTMP in bone metastases of hormone refractory prostate cancer: a phase I/II trial. J. Nucl. Med., 34:1839-1844.

de Klerk, J. M. H.; van Dijk, A. and van het Schip, A. D. et al. (1992), Pharmacokinetics of rhenium-186 after administration of rhenium-186-HEDP to patients with bone metastases. J. Nucl. Med., 33, 646-651.

Deutsch, E.; Broadack, J. and Deutsch, K. (1993), Radiation Synovectomy Revisited. Eur. J. Nucl. Med., 20, 1113 [and references therein].

Eisenhut, M. (1982), Preparation of Re-186 perrhenate for nuclear medical purposes. Int. J. Appl. Radiat. Isot., 33, 99-103.

Farhangi, M.; Holmes, R. A. and Volkert, W. A. et al. (1992), Samarium-153 EDTMP: Pharmaco-kinetics, toxicity and pain response using an escalating dose schedule in treatment of metastatic bone cancer. $J$. Nucl. Med. 33, 1451-1458.

Friedell, H. L. and Storaasli, J. P. (1950), The use of radioactive phosphorus in the treatment of carcinoma of the breast with widespread metastases to bone. Am. J. Roentgenol., 64, 559-575.

Firusian, N.; Mellin, P. and Schmidt, C. G. (1976), Results of ${ }^{89} \mathrm{Sr}$ therapy in patients with carcinoma of the prostate and incurable pain from bone metastases: a preliminary report. J. Urology, 116, 764-768.

Fossa, S. D.; Paus, E. and Lochoff, M. et al. (1992), ${ }^{89}$ Strontium in bone metastases from hormone resistant prostate cancer: palliation effect and biochemical changes. Brit. J. Cancer, 66,177-180.

Goeckler, W. F.; Edwards, B. and Volkert, W. A. et al. (1987), Skeletal localization of Sm-153 chelates: potential therapeutic bone agents. J. Nucl. Med., 28, 495-504.

Katin, M. J.; Salenius, S. A. and Blitzer, P. H. et al. (1993), Hematologic effects of Sr-89 treatment for metastases to bone. Proc. Amer. Soc. Clin. Oncol., 3, 12.
Kennedy, J. M.; Marinelli, L. D. and Woodard, H. Q. (1941), Tracer studies with radioactive phosphorus in malignant neoplastic disease. Radiology, 37, 683-690.

Krishnamurthy, G. T.; Swailem, F. M. and Srivastava, S. C. et al. (1997), Sn-117m(4+)DTPA pharmacokinetics and imaging characteristics in patients with metastatic bone pain. J. Nucl. Med., 38, 230-237.

Lewington, V. J.; McEwan, A. J. and Ackery, D. M. et al. (1991), A prospective, randomized double-blind crossover study to examine the efficacy of strontium89 in pain palliation in patients with advanced prostate cancer metastatic to bone. Eur. J. Cancer, 27, 954-958.

Marshall, J. H. (1972), A model of strontium metabolism in adult man. In- Goldman, $M$. and Bustad, L. K. (eds.). Biomedical implications of radiostrontium exposure. United States Atomic Energy Commission. pp. 68-84.

Mathieu, L.; Chevalier, P.; Gaby, C. and Berger, M. (1979), Preparation of 186-rhenium labeled HEDP and its possible use in the treatment of osseous neoplasm. Int. J. Appl. Radiat. Isot., 30, 725-727.

Maxon, H. R.; Deutsch, E. A. and Thomas, S. R. et al. (1988), Re-186(Sn) HEDP for treatment of multiple metastatic foci in bone: human biodistribution and dosimetric studies. Radiology, 166, 501-507.

Maxon, H. R.; Schroder, L .E. and Thomas, S. R. et al. (1990), Re-186(Sn)HEDP for treatment of painful osseous metastases: Initial clinical experience in 20 patients with hormone-resistant prostate cancer. Radiology, 176, 155-159.

McEwan, A. J. B. (1994), Radiopharmaceuticals for palliative treatment of painful bone metastases. New Perspec. Cancer. Diagn. Management, 1, 24-31.

Oster, Z. H.; Som, P. and Srivastava, S. C. et al. (1995), The development and in-vivo behavior of tin containing radiopharmaceuticals II. Autoradiographic and scintigraphic studies in normal animals and in animal models of disease. Int. J. Nucl. Med. Biol., 12, 175-184.

Pecher, C. (1942), Biological investigations with radioactive calcium and strontium: preliminary report on the use of radioactive strontium in the treatment of bone cancer. University of California Publications in Pharmacology, 11, 117-149.

Porter, A. T.; McEwan, A. J. B. and Powe, J. E. et al. (1993), Results of a randomized phase-II trial to evaluate the efficacy of strontium-89 adjuvant to local field external beam irradiation in the management of endocrine resistant metastatic prostate cancer. Int. J. Radiat. Oncol. Biol. Physics, 25, 805-813.

Quilty, P. M.; Kirk, D. and Bolger, J. J. et al. (1994), A comparison of the palliative effects of strontium-89 and external beam therapy radiotherapy in metastatic prostate cancer. Radiother. Oncol., 31, 33-40. 
Resche, I.; Chatal, J. F. and Pecking, A. et al. (1997), A dose-controlled study of ${ }^{153} \mathrm{Sm}-$ ethylenediaminetetramethylenephosphonate (EDTMP) in the treatment of patients with painful bone metastases. Eur. J. Cancer, 33, 1583-1591.

Robinson, R. G. (1986), Radionuclides for the alleviation of bone pain in advanced malignancy. Clin. Oncol., 5, 39-49.

Robinson, R. G.; Spicer, J. A. and Preston, D. F. et al. (1987), Treatment of metastatic bone pain with strontium-89. Nucl. Med. Biol., 14, 219-222.

Robinson, R. G.; Blake, G. M. and Preston, D. F. et al. (1989), Strontium-89: treatment results and kinetics in patients with painful metastatic prostate and breast cancer in bone. Radiographics, 9, 271-281.

Singh, A.; Holmes, R. A. and Farhangi, M. et al. (1989), Human pharmacokinetics of samarium-153 EDTMP in metastatic cancer. J. Nucl. Med., 30, 1814-1818.

Srivastava, S. C.; Meinken, G. E. and Richards, P. et al. (1985), The development and in-vivo behavior of tin containing radiopharmaceuticals I. Chemistry, preparation and biodistribution in small animals. Int. J. Nucl. Med. Biol., 12, 167-174.

Srivastava, S. C.; Meinken, G. E. and Mausner, L. F. et al. (1994), Nuclear, chemical, and mechanistic considerations in the use of ${ }^{\mathbf{1 1 7} \mathbf{m}} \mathrm{Sn}$ (IV)-DTPA relative to ${ }^{186} \mathrm{Re}$-HEDP and other agents for bone pain therapy. In- Nicolini, M. et al. (eds.). Fourth International Symposium on Technetium in Chemistry and Nuclear Medicine. SG Editoriali, Padova, Italy. pp. 287-292.
Srivastava, S.C. (1996), Therapeutic Radionuclides: Making the Right Choice. In- Mather, S. J. (ed.). Current Directions in Radiopharmaceutical Research and Development. Kluwer Academic Publishers, Dordrecht, The Netherlands. pp. 63-79.

Srivastava, S. C.; Atkins, H. L. and Krishnamurthy, G. T. et al. (1998), Treatment of metastatic bone pain with tin- $117 \mathrm{~m}$ stannic DTPA: A phase I/II clinical study. Clin. Cancer Res., 4, 61-68.

Srivastava, S. C. and Dadachova, E. (2001), Recent Advances in Radionuclide Therapy. Seminars in Nucl. Med., 31, 330-341.

Turner, J. H. and Claringbold, P. G. (1991), A phase II study of painful multifocal skeletal metastases with single and repeated dose samarium-153 ethylenediaminetetramethylene phosphonate. Eur. J. Cancer, 27, 1084-1086.

Uchiyama, M.; Tanaka, G., and Yabumoto, E. (1973), ${ }^{85} \mathrm{Sr}$ retention in Japanese after a single administration. J. Radiat. Res., 14,169-179.

Received: July 18, 2002; Revised: July 20, 2002; Accepted: July 21, 2002. 